\title{
Abordagem preventiva e educativa em paciente odontológico com microcefalia associada ao Zika virus: relato de caso
}

Preventive and educational approach in dental patient with microcephaly associated with Zika virus: case report Enfoque preventivo y educativo en pacientes odontológicos con microcefalia asociada al virus Zika: reporte de caso

\author{
Bruna Satiko de Oliveira KOHASHI ${ }^{1}$ \\ Eliana de Oliveira Aranha RIBEIRO² \\ Keuly Souza SOARES ${ }^{3}$
}

Gimol Benchimol de Resende PRESTES ${ }^{\mathbf{4}}$

${ }^{1}$ Acadêmica do Curso de Graduação em Odontologia, Escola Superior de Ciências da Saúde, Universidade do Estado do Amazonas, UEA 69065-001 Manaus-AM, Brasil ${ }^{2}$ Mestre em Odontologia pela Universidade Federal do Amazonas (UFAM), Doutoranda em Educação, Universidade do Estado do Rio de Janeiro (UERJ) Professora da Escola Superior de Ciências da Saúde, Universidade do Estado do Amazonas, UEA, 69065001 Manaus-AM, Brasil

${ }^{3}$ Especialista em Pacientes Portadores de Necessidades Especiais/Conselho Federal de Odontologia (CFO), Professora da Escola Superior de Ciências da Saúde, Universidade do Estado do Amazonas, UEA, 69065001 Manaus-AM, Brasil

${ }^{4}$ Doutora pelo Programa de Pós-Graduação em Odontologia, Área de Concentração em Odontopediatria, Universidade Federal de Santa Catarina (UFSC) Professora da Escola Superior de Ciências da Saúde, Universidade do Estado do Amazonas, UEA, 69065001 Manaus-AM, Brasil

\section{Resumo}

A microcefalia é uma condição onde o perímetro cefálico do bebê encontra-se consideravelmente menor quando comparada com o de outras crianças do mesmo sexo e idade. Em 2015 registrou-se um aumento no número de crianças nascidas com microcefalia, sendo esta associada ao Zika vírus (ZIKV). Os pacientes com microcefalia normalmente manifestam alterações neurológicas, craniofaciais e bucais. O objetivo deste estudo é descrever as características clínicas da microcefalia associada ao ZIKV e apresentar a abordagem odontológica preventiva e educativa em um paciente com esta patologia. Paciente do gênero masculino, 1 ano e 11 meses de idade, compareceu à Policlínica Odontológica da Universidade do Estado do Amazonas para atendimento. Na anamnese, o responsável relatou que o paciente apresentava microcefalia com atraso no desenvolvimento neuropsicomotor, diagnosticado desde o nascimento. No exame físico foi observada falta de sustentação e encurtamento do pescoço, testa estreita e nariz amplo. Ao exame intrabucal apresentava boa condição de higiene e sem cáries. Foi realizado tratamento preventivo com profilaxia e aplicação tópica de flúor e o responsável recebeu orientações educativas sobre higiene oral. O crescimento do número de pacientes com microcefalia, associado ao fato de que pacientes especiais têm um risco aumentado para desenvolver doenças bucais, mostram a importância da prevenção e educação em saúde odontológica pois estas possibilitarão o condicionamento do paciente, manutenção da saúde bucal, estreitamento do vínculo família-paciente-profissional além de novas perspectivas para a atuação profissional de outros colegas.

Descritores: Microcefalia; Pessoas com Deficiência; Promoção da Saúde; Saúde Bucal; Educação em Saúde.

\begin{abstract}
Microcephaly is a medical condition in wich the baby's head circumference is considerably smaller when compared to other children of the same gender and age. In 2015 there was an increase in the number of children born with microcephaly, which was associated with the Zika virus. Microcephaly's patients usually presents neurological, craniofacial and oral alterations. The objective of this study is to describe the clinical characteristics of microcephaly associated with ZIKV and present the preventive and educational dental approach in a patient with this pathology. A male patient, 1 year and 11 months old, attended at Dental clinic of the Amazonas State University for assistance. In the anamnesis, the sponsor reported that the patient had microcephaly with delayed neuropsychomotor development, diagnosed from birth. At physical exam was observed lack of support and shortening the neck, narrow forehead and large nose. The intrabuccal examination showed good hygiene and no tooth decay. Preventive treatment was performed with prophylaxis and topical fluoride application and the sponsor received educational guidelines on oral hygiene. The increase in the number of patients with microcephaly, associated with disabled are increased risk for developing oral diseases, show us the importance of prevention and education in dental care, since these will enable patient conditioning, oral health maintenance, family-patient-professional link in addition to new perspectives for the professional performance of other colleagues.
\end{abstract}

Descriptors: Microcephaly; Disabled Persons; Health Promotion; Oral Health; Health Education.

\section{Resumen}

La microcefalia es una condición donde el perímetro cefálico del bebé se encuentra considerablemente menor cuando se compara con el de otros niños del mismo sexo y edad. En 2015 se registró un aumento en el número de niños nacidos con microcefalia, siendo esta asociada al Zika virus (ZIKV). Los pacientes con microcefalia normalmente manifiestan alteraciones neurológicas, craneofaciales y bucales. El objetivo de este estudio es describir las características clínicas de la microcefalia asociada al ZIKV y presentar el abordaje odontológico preventivo y educativo en un paciente con esta patología. Paciente del género masculino, 1 año y 11 meses de edad, compareció a la Policlínica Odontológica de la Universidad del Estado de Amazonas para atención. En la anamnesis, el responsable relató que el paciente presentaba microcefalia con retraso en el desarrollo neuropsicomotor, diagnosticado desde el nacimiento. En el examen físico se observó falta de sustentación y acortamiento del cuello, frente estrecho y nariz amplia. En el examen intrabucal presentaba buena condición de higiene y sin caries. Se realizó tratamiento preventivo con profilaxis y aplicación tópica de flúor y el responsable recibió orientaciones educativas sobre higiene oral. El crecimiento del número de pacientes con microcefalia, asociado al hecho de que pacientes especiales tienen un riesgo aumentado para desarrollar enfermedades bucales, muestran la importancia de la prevención y educación en salud odontológica pues éstas van a posibilitar el condicionamiento del paciente, mantenimiento de la salud bucal, estrechamiento del paciente, el vínculo familiarpaciente-profesional además de nuevas perspectivas para la actuación profesional de otros colegas.

Descriptores: Microcefalia; Personas con Discapacidad; Promoción de la Salud; Salud Bucal; Educación en Salud.

\section{INTRODUÇÃO}

A microcefalia é uma condição em que o perímetro cefálico (PC) do bebê encontra-se consideravelmente menor quando comparada com o de outras crianças do mesmo sexo e idade, é um sinal clínico e não uma doença ${ }^{1}$. Pode ser causada por diversos fatores de etiologia genética, como desordens cromossômicas e metabólicas, e também não genéticas, como, por exemplo, as infecções congênitas ${ }^{2}$. O defeito básico dessa condição pode ocorrer porque o cérebro do bebê não se desenvolveu adequadamente durante a gestação ou parou de crescer após o parto, o que resulta em uma menor circunferência cefálica. A Organização Mundial de Saúde recomenda para as primeiras $24-48$ h de vida 
que as medidas para ambos os sexos tenham como referência os parâmetros de InterGrowth. A medida de referência para crianças que nasceram com 37 semanas de gestação será $30,24 \mathrm{~cm}$ para meninas e $30,54 \mathrm{~cm}$ para meninos ${ }^{3}$.

A microcefalia pode acontecer de forma isolada ou com outros defeitos congênitos ${ }^{4,5}$. Os recém-nascidos com microcefalia correm o risco de ter um atraso no desenvolvimento e incapacidade intelectual, podendo também desenvolver convulsões e incapacidades físicas, incluindo dificuldades auditivas e visuais. No entanto, algumas dessas crianças vão ter o desenvolvimento neurológico normal $^{1}$. A microcefalia não tem cura e nem tratamento específico, porém existem ações de suporte que auxiliam no desenvolvimento e que devem ser realizadas na atenção básica ${ }^{6}$. Uma equipe multidisciplinar pode auxiliar a minimizar as sequelas e assegurar mais autonomia e inclusão social $^{7}$.

Em maio de 2015 foi detectada a primeira ocorrência de microcefalia associada ao Zika vírus (ZIKV) em território brasileiro ${ }^{8,9}$. Com a chegada deste surto no Brasil, registrou-se um aumento significativo no número de crianças nascidas com microcefalia ${ }^{10}$. Segundo o Ministério da Saúde, entre 2015 e 2017, o Brasil notificou 15.298 casos de suspeita de crianças com anomalias associadas ao ZIKV, sendo destes, 3.071 o número de casos confirmados ${ }^{11}$. O ZIKV é um arbovírus, transmitido pelo mosquito Aedes aegypti ${ }^{12,13}$.

As principais alterações neurológicas associadas à infecção pelo ZIKV são: hipertonia, persistência ou exagero dos reflexos arcaicos, desproporção craniofacial, alteração de PC/hidrocefalia pela expansão da fontanela anterior, epilepsia/espasmos, irritabilidade/hiperexcitabilidade, alterações visuais e auditivas, dificuldade de deglutição e atraso do desenvolvimento ${ }^{3}$.

Pacientes com necessidades especiais (PNE) são os indivíduos que apresentam qualquer tipo de condição que os faça necessitar de atenção diferenciada por toda sua vida ou parte dela. Assim, os profissionais da área da saúde devem estar preparados e dispostos para oferecer um tratamento adequado e de qualidade de acordo com sua condição específica ${ }^{14}$. Nesse quadro, o cirurgião-dentista (CD) é parte integrante desta equipe.

Muitos pacientes especiais demonstram dificuldade em manter a saúde bucal adequada ou ter acesso ao serviço odontológico devido a uma incapacidade ou condição médica ${ }^{15}$. Outra das razões sobre a dificuldade da atenção odontológica ao PNE é a falta de comunicação e integração entre as demais áreas da saúde e também devido à ausência de métodos educativos e práticos que possibilitem a educação e prevenção dos problemas bucais ${ }^{16}$. Bem como o número reduzido de profissionais especialistas nessa área, somando 668 registros até setembro de 2018, segundo o Conselho Federal de Odontologia.

Os microcéfalos são pacientes especiais e por isso podem apresentar alta incidência de doenças bucais devido à alterações salivares, alimentação pastosa, ingestão constante de carboidratos, uso crônico de medicamentos, falta de habilidade em realizar a própria higiene bucal, movimentos indevidos dos músculos mastigatórios e da língua. Estes são alguns dos fatores de risco que contribuem para a maior prevalência de doenças bucais nesta população ${ }^{17-19}$. Além disso, também apresentam alterações como: maloclusão, micrognatia, atraso na erupção dos dentes, bruxismo e traumatismo dentário ${ }^{20}$.

Como resultado, muitos pacientes com necessidades especiais recebem tratamento odontológico apenas em situações de urgência, no aparecimento de dor, sendo habitual a execução de procedimentos de extração dentária ${ }^{21}$.

$\mathrm{O}$ risco aumentado para desenvolver doenças bucais em PNE justifica a importância da prevenção odontológica nesses pacientes, atuando na informação e integração nos cuidados da criança ${ }^{13}$, nos quais estejam incluídos programas de escovação supervisionada voltada aos pais e cuidadores, orientação dietética e aplicação tópica de flúor $^{22}$, tendo essas medidas a finalidade de criar hábitos e condições saudáveis, e contornar as dificuldades existentes em função de uma limitação.

A educação é um processo que ocorre pela busca gradativa do conhecimento, o qual poderá ser engrandecido a partir da troca de informações e das experiências pessoais. A população brasileira possui pouco conhecimento quanto aos benefícios da prevenção primária no controle e na redução das doenças bucais, dessa forma, para ser possível preveni-las é importante que seja clarificado às pessoas sobre as causas e consequências das doenças bucais $^{23}$.

A educação em saúde é uma prática social, sendo este um exercício que contribui com a construção de hábitos saudáveis, principalmente quando trabalhado na primeira infância, onde os processos de imitação são muito mais frequentes e é nessa idade onde o que a criança aprende, costuma permanecer por toda a vida ${ }^{24,25}$.A educação em saúde altera o comportamento das pessoas em favor da sua própria saúde e da saúde do outro, e é papel dos profissionais de saúde oferecer orientações sobre mudanças necessárias para alcançar tal objetivo ${ }^{23}$.

$\mathrm{O}$ tratamento odontológico se fundamenta em suprimr ou contornar as dificuldades existentes diante de uma limitação, seja de ordem mental, física, sensorial, comportamental e de crescimento. Uma condição bucal satisfatória do paciente com necessidade especial está diretamente relacionada à 
presença de um cuidador, para que este possa realizar e auxiliar em suas atividades diárias, como por exemplo de escovação. Dessa forma programas para promoção de saúde bucal do PNE são favoráveis ao condicionamento do paciente, pois propiciam a manutenção da saúde e possibilitam o estreitamento do vínculo família-paciente-profissional ${ }^{14}$.

$\mathrm{O}$ atendimento odontológico de pacientes com necessidades especiais exige certos cuidados habilidades para que o tratamento possa ocorrer de forma eficaz ${ }^{26}$, e o cirurgião-dentista tem um papel essencial no planejamento e condução do tratamento, evitando que as doenças bucais tenham um impacto negativo, tornando assim possível a manutenção da saúde geral do paciente. É importante que a atenção odontológica ao PNE seja efetuada o mais cedo possível para tornar realizável a prevenção de problemas futuros e de maiores dimensões, além de criar hábitos que irão perdurar por toda a vida do paciente $^{14}$.

A atuação do cirurgião-dentista na promoção de saúde de PNE é de suma importância no estabelecimento da saúde bucal e integral desses pacientes. O objetivo deste estudo é descrever as características clínicas da microcefalia associada ao ZIKV e apresentar a abordagem odontológica preventiva e educativa em um paciente com esta patologia.

\section{CASO CLÍNICO}

Paciente do gênero masculino, 1 ano e 11 meses de idade, feoderma, chegou à clínica de pacientes especiais da Policlínica Odontológica da Universidade do Estado do Amazonas (UEA) acompanhado do responsável para seu primeiro atendimento odontológico. Após assinatura do termo de consentimento livre e esclarecido (TCLE) pelo responsável do paciente, iniciou-se o atendimento. $\mathrm{Na}$ anamnese, o acompanhante relatou que o paciente apresentava microcefalia associada ao ZIKV e fazia uso de Fenobarbital (anticonvulsivante) e Vigabatrina (controle de espasmos infantis). No exame físico, observou-se atraso no desenvolvimento, falta de firmeza na sustentação do pescoço e encurtamento, testa estreita e nariz amplo (Figura 1).

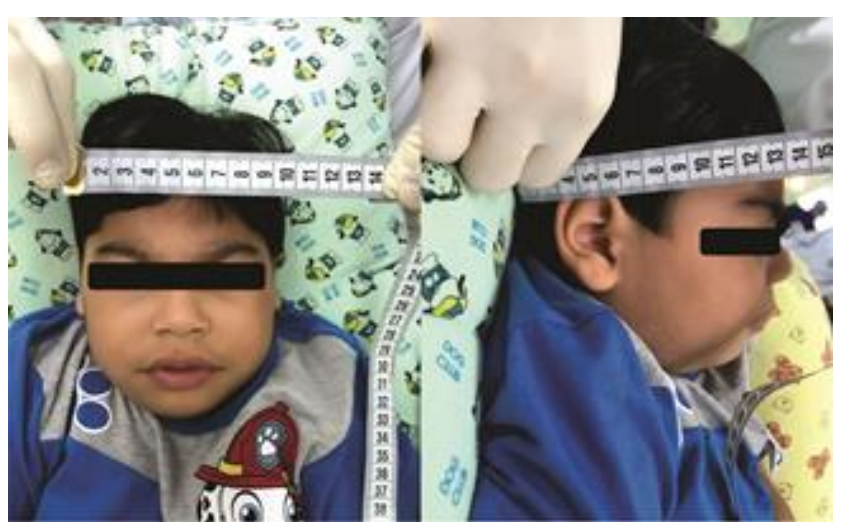

Figura 1: Características de pescoço curto, testa estreita e nariz amplo.
Foi feita a medição do perímetro cefálico (Figura 2), onde foi verificado que o mesmo encontra-se menor que o esperado para a idade e sexo, apresentando $44,1 \mathrm{~cm}$, onde o ideal seria $48,1 \mathrm{~cm}$ e sendo aceitável até -2 ou +2 escores (Tabela 1 ).

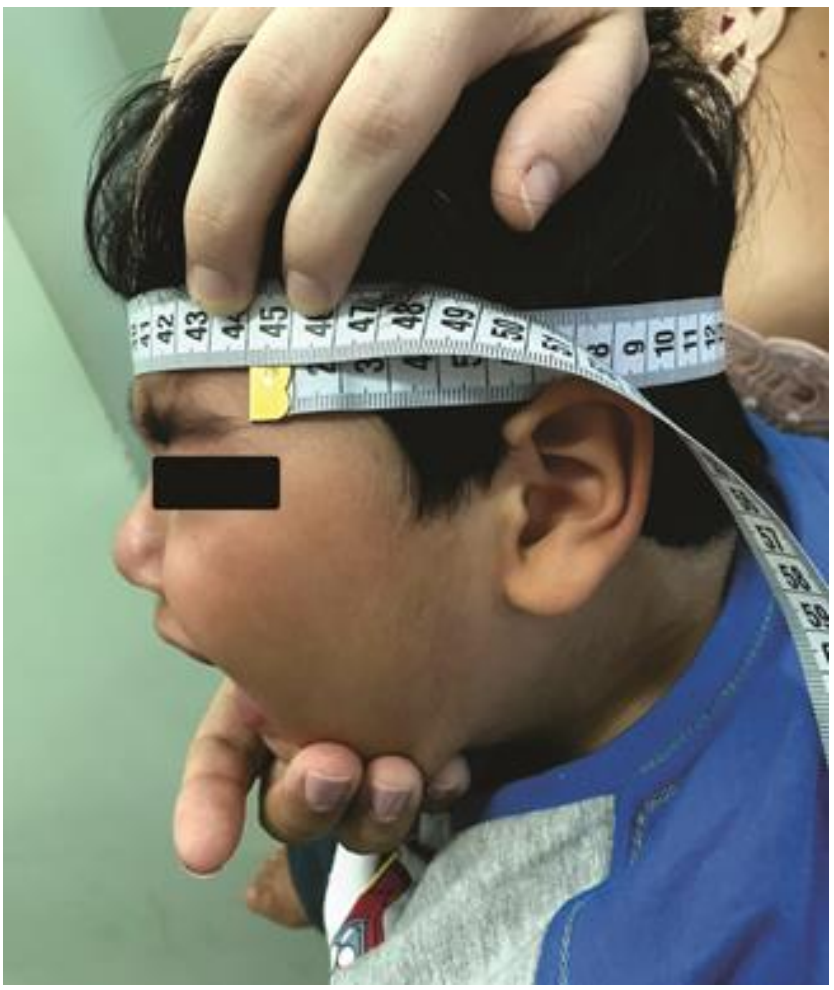

Figura 2: Medição do perímetro cefálico.

Tabela 1. Valores de referência do perímetro cefálico - meninos 0 a 2 anos $(\mathrm{cm})$

\begin{tabular}{c|c|c|c|c|c|c|c}
\hline \multicolumn{7}{c}{ Perímetro cefálico por idade - MENINOS } \\
\multicolumn{7}{c}{ 0 a 2 anos (Z-scores) } \\
\hline Ano: Mês & -3 & -2 & -1 & 0 & 1 & 2 & 3 \\
\hline $0: 0$ & 30,7 & 31,9 & 33,2 & 34,5 & 35,7 & 37,0 & 38,3 \\
\hline $0: 1$ & 33,8 & 34,9 & 36,1 & 37,3 & 38,4 & 39,6 & 40,8 \\
\hline $0: 2$ & 35,6 & 36,8 & 38,0 & 39,1 & 40,3 & 41,5 & 42,6 \\
\hline $0: 3$ & 37,0 & 38,1 & 39,3 & 40,5 & 41,7 & 42,9 & 44,1 \\
\hline $0: 4$ & 38,0 & 39,2 & 40,4 & 41,6 & 42,8 & 44,0 & 45,2 \\
\hline $0: 5$ & 38,9 & 40,1 & 41,4 & 42,6 & 43,8 & 45,0 & 46,2 \\
\hline $0: 6$ & 39,7 & 40,9 & 42,1 & 43,3 & 44,6 & 45,8 & 47,0 \\
\hline $0: 7$ & 40,3 & 41,5 & 42,7 & 44,0 & 45,2 & 46,4 & 47,7 \\
\hline $0: 8$ & 40,8 & 42,0 & 43,3 & 44,5 & 45,8 & 47,0 & 48,3 \\
\hline $0: 9$ & 41,2 & 42,5 & 43,7 & 45,0 & 46,3 & 47,5 & 48,8 \\
\hline $0: 10$ & 41,6 & 42,9 & 44,1 & 45,4 & 46,7 & 47,9 & 49,2 \\
\hline $0: 11$ & 41,9 & 43,2 & 44,5 & 45,8 & 47,0 & 48,3 & 49,6 \\
\hline $1: 0$ & 42,2 & 43,5 & 44,8 & 46,1 & 47,4 & 48,6 & 49,9 \\
\hline $1: 1$ & 42,5 & 43,8 & 45,0 & 46,3 & 47,6 & 48,9 & 50,2 \\
\hline $1: 2$ & 42,7 & 44,0 & 45,3 & 46,6 & 47,9 & 49,2 & 50,5 \\
\hline $1: 3$ & 42,9 & 44,2 & 45,5 & 46,8 & 48,1 & 49,4 & 50,7 \\
\hline $1: 4$ & 43,1 & 44,4 & 45,7 & 47,0 & 48,3 & 49,6 & 51,0 \\
\hline $1: 5$ & 43,2 & 44,6 & 45,9 & 47,2 & 48,5 & 49,8 & 51,2 \\
\hline $1: 6$ & 43,4 & 44,7 & 46,0 & 47,4 & 48,7 & 50,0 & 51,4 \\
\hline $1: 7$ & 43,5 & 44,9 & 46,2 & 47,5 & 48,9 & 50,2 & 51,5 \\
\hline $1: 8$ & 43,7 & 45,0 & 46,4 & 47,7 & 49,0 & 50,4 & 51,7 \\
\hline $1: 9$ & 43,8 & 45,2 & 46,5 & 47,8 & 49,2 & 50,5 & 51,9 \\
\hline $1: 10$ & 43,9 & 45,3 & 46,6 & 48,0 & 49,3 & 50,7 & 52,0 \\
\hline $1: 11$ & 44,1 & 45,4 & 46,8 & 48,1 & 49,5 & 50,8 & 52,2 \\
\hline $2: 0$ & 44,2 & 45,5 & 46,9 & 48,3 & 49,6 & 51,0 & 52,3 \\
\hline \hline Fo & & & & & & \\
\hline
\end{tabular}

Fonte: Organização Mundial de Saúde, 2018.

Notou-se que o paciente fazia uso de órteses tornozelo-pé AFO (ankle-footorthesis) (Figura 3), para controlar o alinhamento e a movimentação dos pés e tornozelos. Para a realização do exame intraoral foram usadas almofadas para adaptação do paciente na cadeira odontológica (Figura 4), também conhecida como "calça da vovó", um tipo de facilitador muito usado no atendimento de pacientes 
com comprometimento neuromotor que permite o correto posicionamento na cadeira odontológica, ao mesmo tempo em que traz conforto ao paciente, tornando possível um bom atendimento.

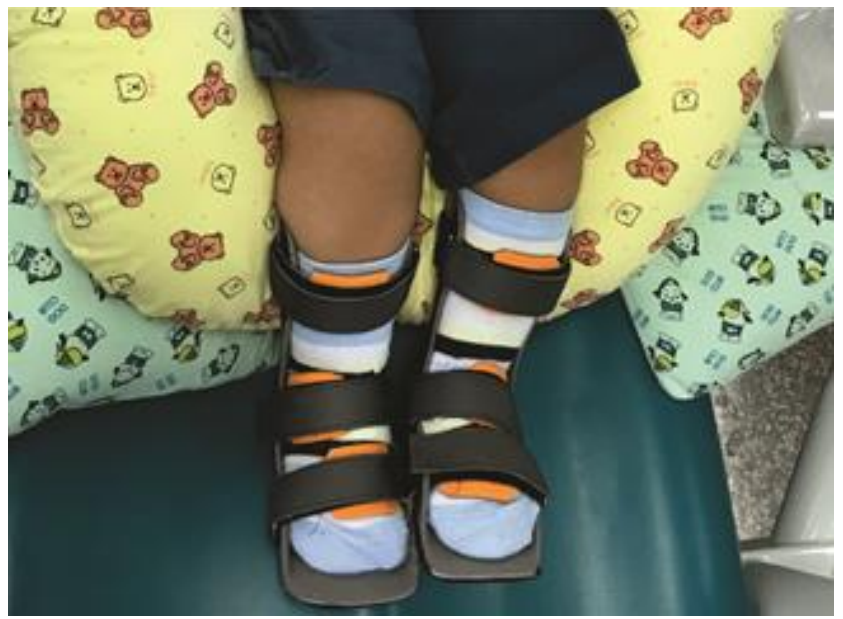

Figura 3: Paciente fazendo uso das órteses tornozelo-pé.

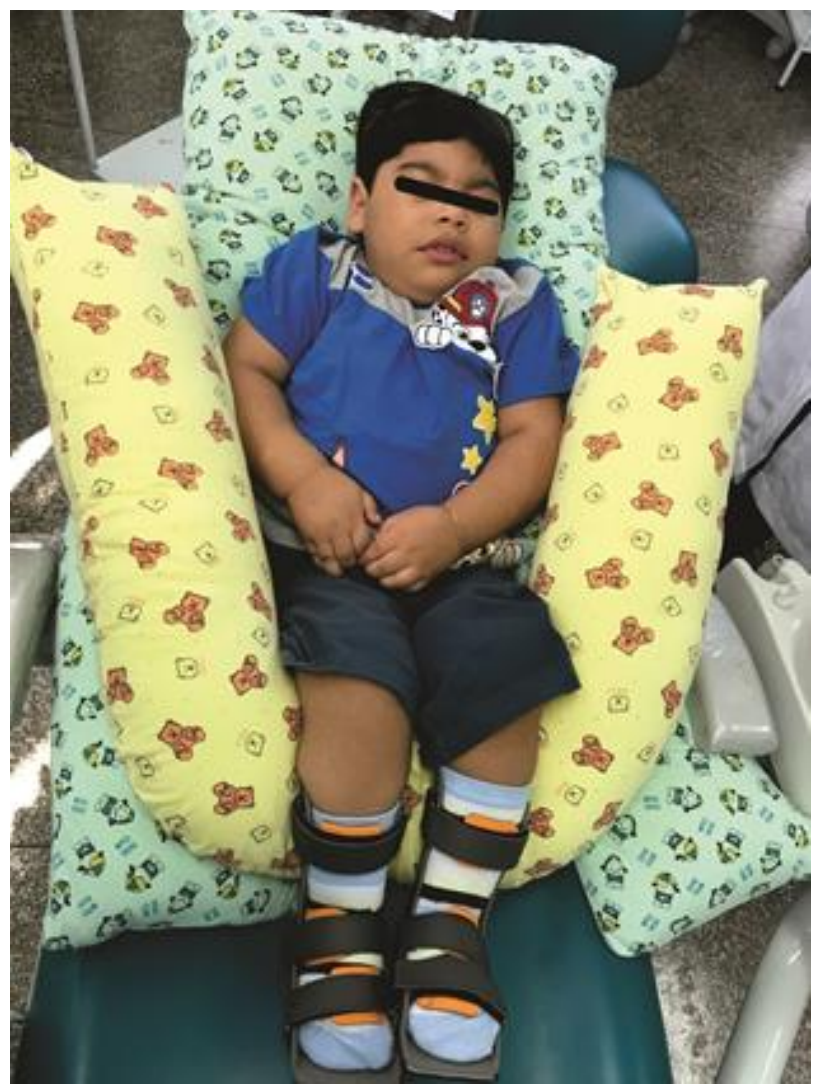

Figura 4: Paciente posicionado na "calça da vovó".

Ao exame intraoral com o auxílio de espátulas de madeira e espelho clínico, observou-se que o paciente apresentava boa condição de higiene e sem cáries. Não foi constatado nenhuma anormalidade quanto à erupção dos elementos dentários e os mesmos apresentaram-se todos hígidos, ainda que com leves desgastes em face incisal dos elementos 62 e 71 (Figura 5). O plano de tratamento proposto foi o preventivo com profilaxia e aplicação tópica de flúor e o responsável recebeu orientações educativas sobre higiene oral, salientando a importância da manutenção da saúde bucal (Figuras 6 e 7). A pasta profilática utilizada para profilaxia foi a Shine (Maquira Dental, Maringá, Paraná, Brasil) e a aplicação tópica com Fluorsul Gel (Iodontosul, Porto Alegre, Rio Grande do Sul, Brasil). O paciente está agendado com consultas regulares semestrais, para proservação e manutenção da boa saúde oral.

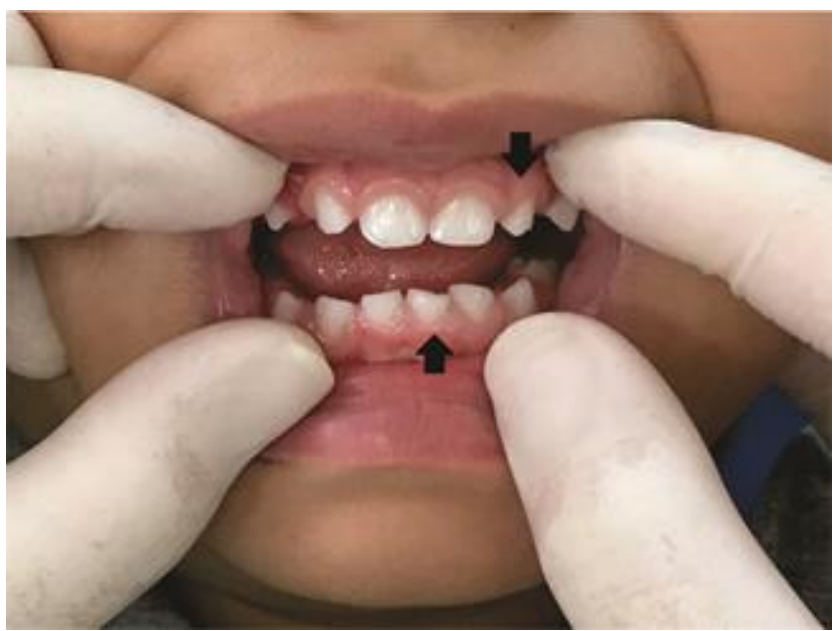

Figura 5: Leve desgaste dentário dos elementos 62 e 71.

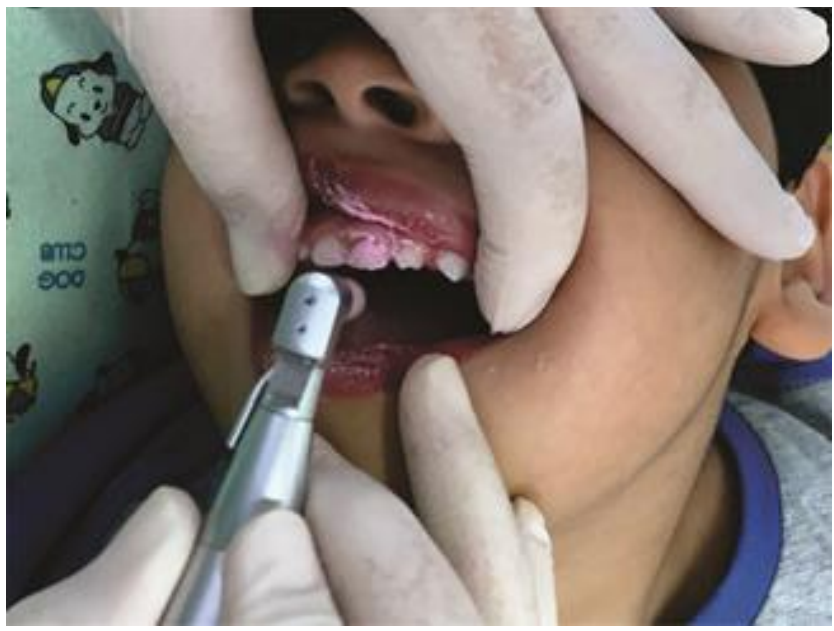

Figura 6: Realização da profilaxia dentária.

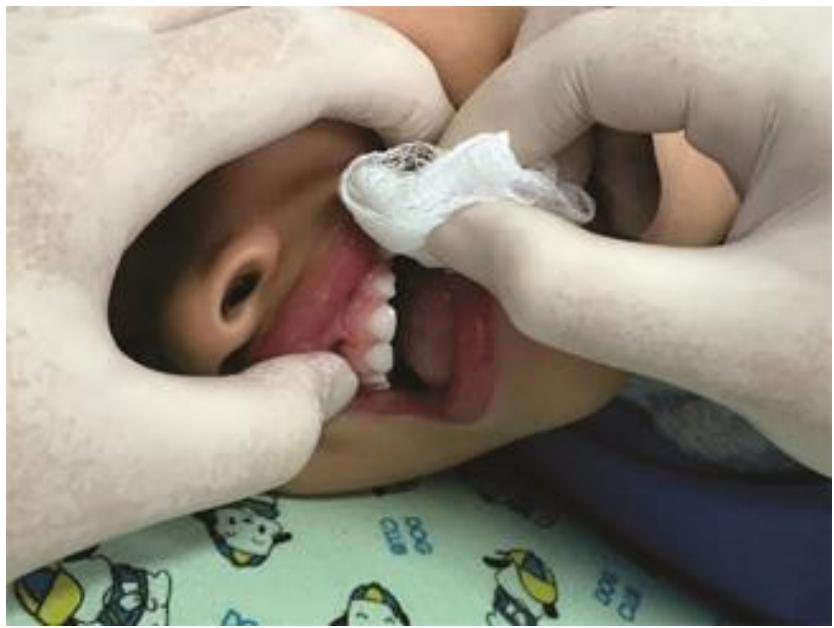

Figura 7: Realização da aplicação tópica de flúor.

\section{DISCUSSÃO}

Algumas alterações motoras ou cognitivas decorrentes de modificações do Sistema Nervoso Central e/ou de malformações congênitas, podem comprometer a respiração, a deglutição e a 
mastigação ${ }^{3}$, fazendo com que os pacientes precisem de alimentos mais pastosos e hipercalóricos, e devido a textura, ficam retidas mais facilmente nos dentes, caracterizando uma tendência à cárie ${ }^{27}$. No paciente em questão, a dieta consiste em alimentos mais líquidos e pastosos, porém a higienização bucal adequada contribui para que não haja comprometimento da saúde bucal, estando este livre de cáries.

A testa um pouco mais estreita, nariz amplo e pescoço curto $^{28}$, são sinais compatíveis com o paciente e condizem com as características da microcefalia descritas na literatura. Há relatos de microcéfalos que apresentam retrognatismo ${ }^{28} \mathrm{e}$ micrognatia, problemas que podem levar ao apinhamento dentário e macroglossia secundária, assim como também anomalias palatais ${ }^{29}$, porém essas características clínicas divergem do paciente em questão.

A hipotonia ou hipertonia muscular que ocorre nos microcéfalos gera um atraso no desenvolvimento neuromotor que incapacita o paciente de realizar seus cuidados bucais $^{30} \mathrm{e}$ atividades de vida diária. Estes pacientes necessitam então de um cuidador para realização destas atividades e para alcançar uma condição bucal satisfatória ${ }^{14}$. O paciente deste relato tem sua higiene realizada pela mãe, corroborando assim com os autores.

É unânime que o auxílio profissional precoce é mais eficaz. Na literatura são encontrados diversos artigos que discorrem sobre a importância da criação programas de saúde bucal voltado especificamente para pacientes com necessidades especiais ${ }^{31}$. Dados ratificados com esse estudo uma vez que esta foi a primeira consulta odontológica do paciente, onde foi trabalhado instruções de higiene bucal, técnicas de escovação e métodos alternativos para facilitar o desenvolvimento dessa atividade, além de incentivar e elogiar o cuidador pelo belo desempenho que obteve até então. É certo que quanto mais cedo se trabalhar desta forma, mais os pacientes se mostram cooperativos e com tendência a perpetuar os hábitos adquiridos $^{31}$.

\section{CONCLUSÃO}

A microcefalia associada ao ZIKV é uma condição que pode representar dificuldade ao cirurgião-dentista, devido à escassez de informação sobre o manejo adequado destes pacientes para o atendimento odontológico e ao número reduzido de profissionais capacitados para atender estes pacientes.

Os microcéfalos podem apresentar diversas alterações bucodentárias devido ao comprometimento do desenvolvimento neuropsicomotor, às alterações neurológicas e craniofaciais, à dieta e alterações salivares. Assim a atuação preventiva do cirurgião- dentista, tem como função evitar problemas odontológicos futuros e de maiores dimensões, além de estabelecer um plano de tratamento adequado para possibilitar a prevenção das doenças bucais por meio da educação, contornando as dificuldades existentes.

Portanto é fundamental que os CDs envolvidos nos tratamentos destes pacientes conheçam as limitações existentes devido a patologia e que adotem condutas necessárias de ordem geral, bucal e comportamental, a fim de superar todas as barreiras apresentadas para realização do atendimento odontológico.

\section{REFERÊNCIAS}

1. World Health Organization. Screening, assessment and management of neonates and infants with complications associated with Zika virus exposure in utero: rapid advice guideline. WHO 2016: 1-15.

2. Ashwal S, Michelson D, Plawner L, Dobyns WB, Quality Standards Subcommittee of the American Academy of Neurology and the Practice Committee of the Child Neurology Society. Practice parameter: Evaluation of the child with microcephaly (an evidence-based review): report of the Quality Standards Subcommittee of the American Academy of Neurology and the Practice Committee of the Child Neurology Society. Neurology 2009;73(11):887-97.

3. BRASIL. Secretaria de Vigilância em Saúde. Secretaria de Atenção à Saúde. Orientações integradas de vigilância e atenção à saúde no âmbito da Emergência de Saúde Pública de Importância Nacional: procedimentos para o monitoramento das alterações no crescimento e desenvolvimento a partir da gestação até a primeira infância, relacionadas à infecção pelo vírus Zika e outras etiologias infeciosas dentro da capacidade operacional do SUS. Brasília: Ministério da Saúde 2017.

4. Lopez-Camelo JS, Orioli IM, Castilla E. Documento ECLAMC Final: Resumo e Conclusões dos Documentos 1-5. Buenos Aires 2015; 3.

5. Butler D. Microcephaly surge in doubt. Nature. 2016; 530(7588):13-15.

6. Veiga SA, Nunes CR, Andrade CCF. Assistência de enfermagem à criança com microcefalia. Múltiplos Acessos 2017;2(2):116-28.

7. COFFITO. Sistema COFFITO/CREFITOs. Diagnóstico: Microcefalia. E agora?. 2016: 1-12.

8. Oliveira Melo AS, Malinger G, Ximenes R, Szejnfeld PO, Alves Sampaio S, Bispo de Filippis AM. Zika virus intrauterine infection causes fetal brain abnormality and microcephaly: tip of the iceberg? Ultrasound Obstet Gynecol. 2016;47(1):6-7.

9. Campos GS, Bandeira AC, Sardi SI. Zika Virus 
Outbreak, Bahia, Brazil. Emerg Infect Dis. 2015; 21(10):1885-86.

10.BRASIL. Secretaria de Vigilância em Saúde. Vírus Zika no Brasil: a resposta do SUS. Brasília: Ministério da Saúde 2017.

11.BRASIL. Boletim Epidemiológico Secretaria de Vigilância em Saúde. Ministério da Saúde 2018; 49(6): 1-10.

12.Besnard M, Lastére S, Teissier A, Cao-Lormeau V, Musso D. Evidence of perinatal transmission of Zika vírus, French Poliynesia, December 2013 and February 2014. Euro Survell. 2014;19(13): pii 20751.

13. Henriques CMP, Duarte E, Garcia LP. Desafios para o enfrentamento da epidemia de microcefalia. Epidemiol Serv Saúde. 2016; 25(1):7-10.

14. Oliveira ALBM, Giro EMA Importância da abordagem precoce no tratamento odontológico de pacientes com necessidades especiais. Odonto. 2011; 19(38):45-51.

15.Glassman P, Caputo A, Dougherty N, Lyons R, Messieha Z, Miler C et al. Special Care Dentistry Association consensus statement on sedation, anesthesia and alternative techniques for people with special needs. Spec Care Dentist. 2009;29(1):2-8.

16. Andrade APP, Eleutéio ASL. Pacientes portadores de necessidades especiais: abordagem odontológica e anestesia geral. Revista bras odontol.. 2016;72(1/2):66-9.

17.Zarvos ML. Microcefalia: um desafio (também) para a Odontologia Brasileira. Disponível em: http://www. cfo.org.br/todas-as-noticias/artigo-2. Acesso em: 06 ago. 2018.

18. Storhaugh K, Holst D. Caries experience of disabled school-aged children. Community Dent Oral Epidemiol. 1987;15(3):144-48.

19.Guaré Rde O, Ciamponi AL. Dental caries prevalence in the primary dentition of cerebral palsied children. J Clin Pediatr Dent. 2003; 27(3):287-92.

20.Leite CN, Varellis MLZ. Microcefalia e a odontologia brasileira. J Health NPEPS. 2016; 1(2):297-304.

21.Camargo MAR. Estudo da prevalência da cárie em pacientes portadores de paralisia cerebral [dissertação]. São Paulo: Faculdade de Odontologia da USP; 2005.

22. Abreu MHNG, Castilho LS, Resende VL. Assistência odontológica a indivíduos portadores de deficiências: o caso da Associação Mineira de Reabilitação e Escola Estadual João Moreira Salles. Arq Odontol. 2001;37(2):153-61.

23. Marcelino G, Parrilha VA. Educação em saúde bucal para mães de crianças especiais: um espaço para a prática dos profissionais de enfermagem. Cogitare Enferm. 2007;12(1):37-43.
24.Bova VBR, Wall ML. Educação em saúde no trânsito: uma contribuição da enfermagem. Cogitare Enferm. 2005;10(1):60-5.

25.Figueiredo MC, Leonardi F, Ecke V. Avaliação do perfil dos pacientes com deficiência atendidos na Faculdade de Odontologia da UFRGS. Rev ACBO. 2016;5(1):1-21.

26.Dao LP, Zwetchkenbaum $S$, Inglehart MR. General dentists and special needs patients: does dental education matter? J Dent Educ. 2005; 69(10): 1107-15.

27.Lemos CAA, Giorgi JDSJ. Zika X MicrocefaliaConsequências Bucais, e Agora Odontologia o que Fazer? II Simpósio de Produção Docente e Discente Universidade Anhanguera de São Paulo; 2017.

28.Morava E, Zeevaert R, Korsch E, Huijben K, WopereisS, Matthijs G et al. A common mutation in the COG7 gene with a consistent phenotype including microcephaly, adducted thumbs, growth retardation, VSD and episodes of hyperthermia. Eur J Hum Genet. 2007;15(6):638-45.

29. Morava E, Lefeber DJ, Urban Z, de Meirleir L, Meinecke P, Gillessen Kaesbach GG et al. Defining the phenotype in an autosomal recessive cutis laxa syndrome with a combined congenital defect of glycosylation. Eur J Hum Genet. 2008;16(1):28-35.

30.Pereira SMS, Borba ASM, Rosa JFL, Carvalho CN, Maia Filho EM, Ferreira MC et al. Zika Vírus e o futuro da Odontologia no atendimento a pacientes com microcefalia. Rev Investig Bioméd São Luís. 2017;9(1):58-66.

31.Abreu KCS, Franco SBO, Calheiros PR. Abordagem odontológica para pacientes portadores de distúrbios neuropsicomotores. FACIMED. 2009. Disponível em: http://www.facimed.edu.br/o/revista/pdfs/31b1d0 bc6502190f69ab2e62163d9a2b.pdf. Acesso em: 06 ago. 2018.

\section{CONFLITO DE INTERESSES}

Os autores declaram não haver conflitos de interesse.

\section{AUTOR PARA CORRESPONDENCIA}

\section{Gimol Benchimol de Resende Prestes}

gresende@uea.edu.br

Submetido em 03/09/2018

Aceito em 04/10/2018 